\section{A case of pyogenic granuloma of the cecum treated by endoscopic resection}

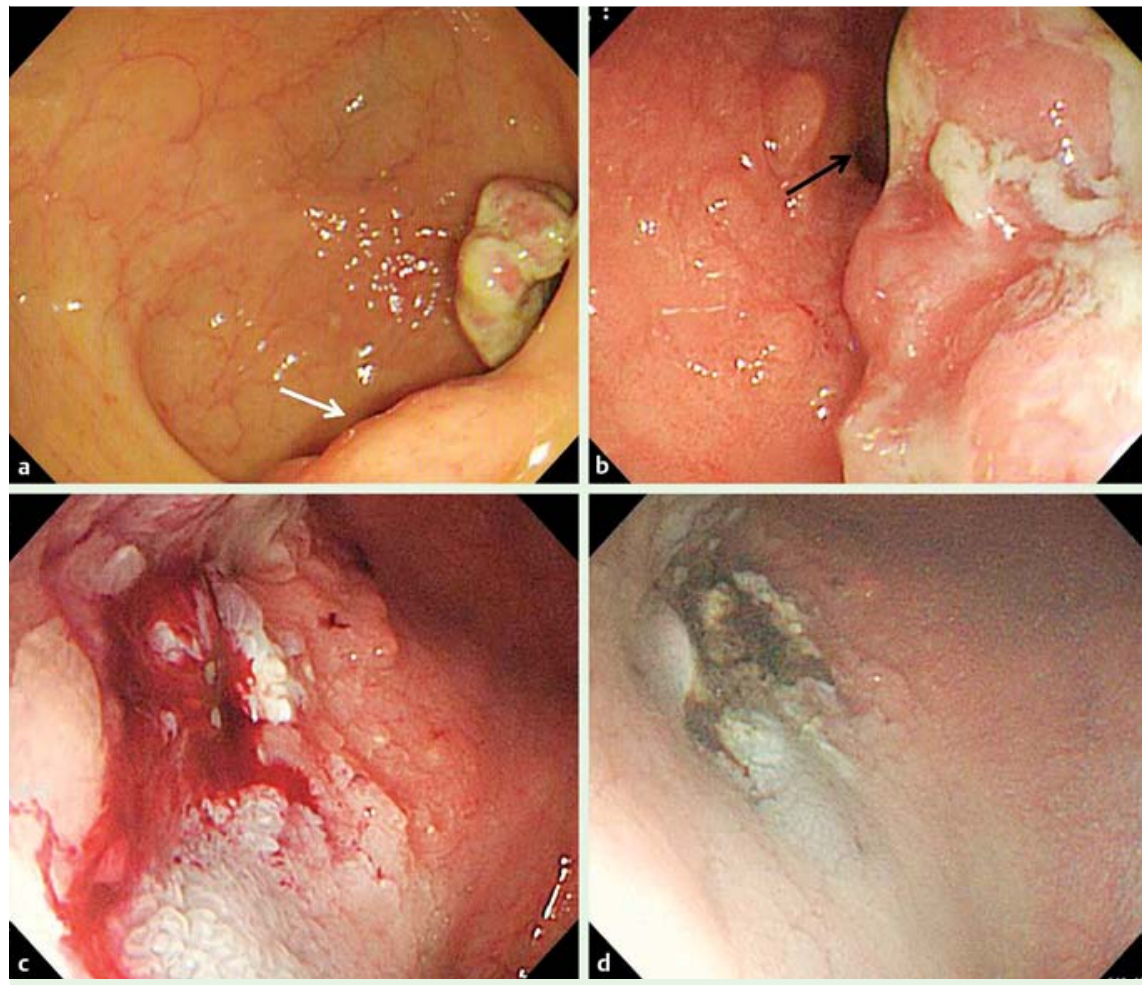

Fig. 1 Colonoscopy views showing: a a pedunculated polyp (approximately $25 \mathrm{~mm}$ ) with a lobulated contour, hypervascular appearance, and covered with an adherent white exudate, and the surrounding mosaic-pattern mucosa with white spots close to the ileocecal valve (white arrow); $\mathbf{b}$ the same polyp and the nearby appendiceal orifice (black arrow); $\mathbf{c}$ minor bleeding after resection of the tumor with a polypectomy snare; $\mathbf{d}$ the resection site after the bleeding had been controlled by the application of electrocoagulation.
A 45-year-old man presented with hematochezia during the 3 days prior to his admission. His past history included hemophilia without any major bleeding events. His vital signs were stable and his physical examination was unremarkable. Initial laboratory findings revealed a hemoglobin of $8.6 \mathrm{~g} / \mathrm{dL}$, hematocrit of $40.3 \%$, platelet count of $336 \times 10^{9} / \mathrm{L}$, prothrombin time of 11.9 seconds, and activated partial thromboplastin time (aPTT) of $49.4 \mathrm{sec}$ onds.

Esophagogastroduodenoscopy (EGD) showed no specific findings. Colonoscopy showed a pedunculated polyp of approximately $25 \mathrm{~mm}$, which had a lobulated contour, hypervascular appearance, and was covered with an adherent white exudate, and the surrounding mosaic-pattern mucosa with white spots ( $\bullet$ Fig. $\mathbf{1}$ a, b). It was difficult to exclude malignancy and biopsies were taken.

Histopathology showed inflammatory granulation tissue and elective endoscopic snare polypectomy was performed. After the polyp had been resected, minor bleeding occurred ( Fig.1c), which ceased after electrocoagulation ( $\bullet$ Fig. $1 \mathrm{~d}$ ). Microscopic examination of the resected polyp showed a highly vascular proliferation that resembled granulation tissue and an inflammatory cell infiltrate with stromal edema, which was consistent with a pyogenic granuloma ( Fig.2). After treatment, the patient's hemoglobin improved gradually and he has remained in a stable condition with no further episodes of bleeding in the 6 months since his discharge.
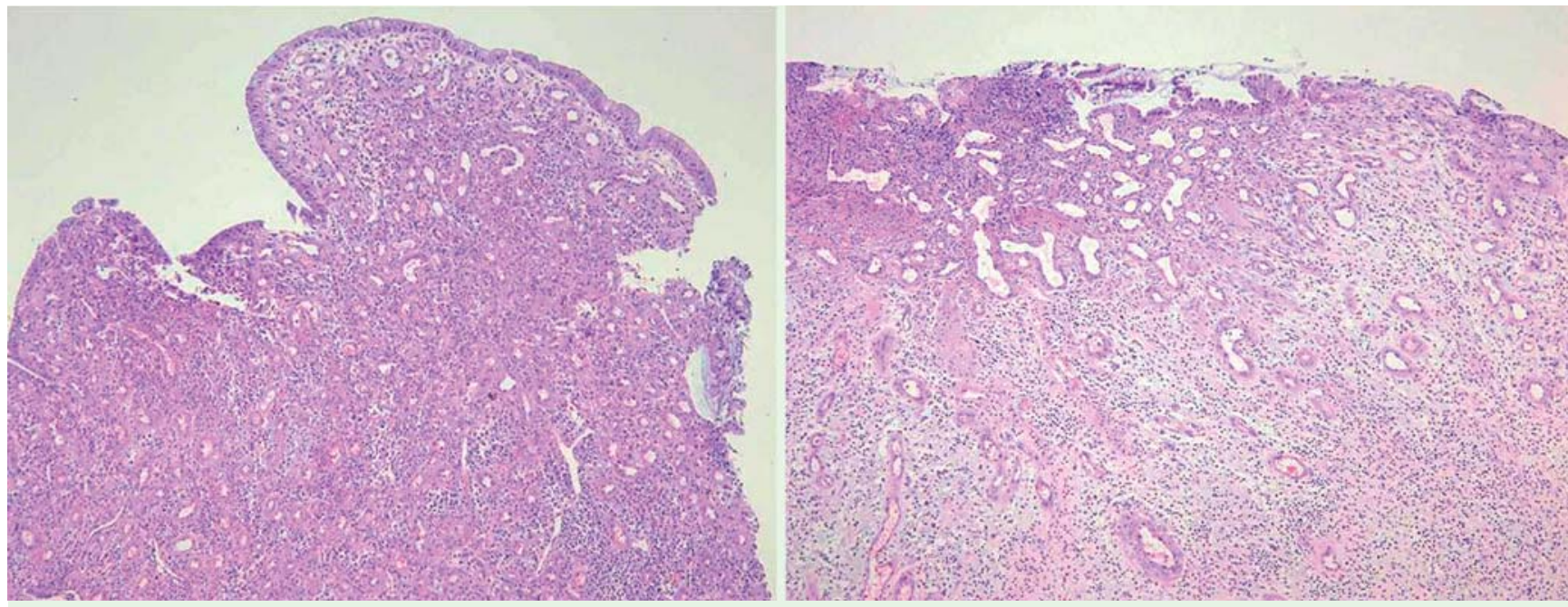

Fig.2 Histology showing a highly vascular proliferation resembling granulation tissue and an inflammatory cell infiltrate with stromal edema (hematoxylin and eosin stain, magnification $\times 100)$. 
A pyogenic granuloma is a specific type of capillary hemangioma that resembles granulation tissue and usually occurs in the skin. The macroscopic and microscopic features of a pyogenic granuloma in the gastrointestinal tract are similar to those seen in the skin [1]. Pyogenic granulomas are benign lesions of uncertain etiology and their pathogenesis has been related to an infectious origin or they may be a special type of hemangioma, while other authors believe that they develop as a result of repetitive trauma or injury, with a possible association with hemophilia, or through a hormonal mechanism for pyogenic granuloma during pregnancy $[1,2]$.

A gastrointestinal pyogenic granuloma, although rare, can be a source of obscure or overt bleeding from the gastrointestinal tract. To the best of our knowledge, no cases of pyogenic granuloma of the cecum have previously been reported in the English literature. Treatments for gastrointestinal pyogenic granuloma include endoscopic polypectomy, surgical resection, argon plasma coagulation, and angiographic embolization [1,3]. In summary, we report the first case of a pyogenic granuloma in the cecum, which was successfully treated with endoscopic snare polypectomy, with no further bleeding after the patient was discharged.

$$
\text { Endoscopy_UCTN_Code_CCL_1AD_2AC }
$$

Competing interests: None

\section{Chang Jun Shin, Seung Goun Hong, Mahn Lee}

Department of Internal medicine, SAM Anyang Hospital, Gyeonggi, South Korea

\section{References}

1 Morita T, Tamura S, Okawauchi Ket al. A case of pyogenic granuloma in the sigmoid colon treated with argon plasma coagulation. Dig Endosc 2005; 17: 253-256

2 Heim $M$, Schapiro J, Wershavski $M$ et al. Drug-induced and traumatic nail problems in the haemophilias. Haemophilia 2000; 6 : $191-194$

3 Chen TC, Lien JM, Ng KF et al. Multiple pyogenic granulomas in sigmoid colon. Gastrointest Endosc 1999; 49: 257-259

\section{Bibliography}

DOI http://dx.doi.org/

10.1055/s-0034-1365788

Endoscopy 2014; 46: E277-E278

(c) Georg Thieme Verlag KG

Stuttgart · New York

ISSN 0013-726X

\section{Corresponding author}

Seung Goun Hong, MD

Department of Internal medicine SAM Anyang Hospital

613-9 Anyang 5 dong, Manan-gu

Gyeonggi 430-733

South Korea

Fax: +82-31-4490151

permi@naver.com 